\title{
Giant Aplysia Neuron R2 Reliably Forms Strong Chemical Connections In Vitro ${ }^{1}$
}

\author{
SAMUEL SCHACHER, $\neq^{2}{ }^{2}$ STEPHEN G. RAYPORT, $\ddagger$ AND RICHARD T. AMBRON ${ }^{\star}$
}

Departments of Anatomy and *Cell Biology, and $\ddagger$ Psychiatry, and Center for Neurobiology and Behavior, College of Physicians and Surgeons, Columbia University and New York State Psychiatric Institute, New York, New York 10032

\begin{abstract}
The giant cholinergic neuron $\mathrm{R} 2$ of Aplysia was cultured in combination with identified neurons L11 and R15 and members of a group of left upper quadrant (LUQ) cells L2 to L6 from the abdominal ganglion. All of these neurons receive cholinergic input from other cells in vivo, but not from R2. In vitro, $\mathbf{R} 2$ reliably formed unidirectional chemical connections with these cells. Single action potentials in R2 produced a dual fast and slow inhibitory response in LUQ cells (L2 to L6), a dual fast inhibitory-slow excitatory response in L11, and a slow inhibitory response in $\mathrm{R15}$. The connections formed on LUQ cells were characteristic of their cholinergic input, but the R2-L11 and the R2-R15 connections also had noncholinergic properties. Thus, unlike L10 which forms connections only with its normal targets in vitro, R2 forms strong chemical connections with other neurons which are not found in vivo. The properties of the $\mathrm{R} 2$ connections also suggest that it may release another neurotransmitter besides acetylcholine.
\end{abstract}

A fundamental property of the nervous system is the specificity of connections between neurons and their central or peripheral targets. Although still being explored, several parameters have been proposed to play key roles in specifying connections. The spatialtemporal sequence of axonal outgrowth and neurogenesis could limit the number of available target cells during the formation of connections between distant neuronal populations (LoPresti et al., 1973; Rakic, 1973; Anderson, 1978; Flaster and Macagno, 1984). Additional interactions, such as the distribution of cell-cell recognition factors on membrane surfaces (see Gottlieb and Glaser, 1980, and Edelman, 1983, for reviews), the release of trophic substances that have selective effects on the presynaptic and/or postsynaptic cells (Christian et al., 1978; Jessell et al., 1979; Salpeter et al., 1982; Sanes et al., 1984), and the effect of neuronal activity in stabilizing

Received October 8, 1984; Revised April 3, 1985;

Accepted April 10, 1985

1 This work was supported by National Science Foundation Grant 15948 to S. S. National Institutes of Health Grants 14555 and 00350 to R. T. A., and National Institutes of Health Grant GM 32099 which supports the mariculture facility at the Marine Biological Laboratory (Woods Hole, MA). We wish to thank R. Wolley and L. Katz for their technical assistance, T. Capo and $\mathrm{S}$. Perritt for raising the animals in this study, and A. Krawetz and $\mathrm{H}$. Ayers for typing the manuscript. We also thank Drs. M. Flaster and J. Koester for their helpful comments on earlier drafts of this manuscript.

${ }^{2}$ To whom correspondence should be addressed, at Center for Neuro biology and Behavior, Columbia University and New York State Psychiatric Institute, 722 West 168th Street, New York, NY 10032. some pre-existing connections while eliminating other connections (Changeaux and Danchin, 1976; Purves and Lichtman, 1980; Harris, 1981; Archer et al., 1982; Thompson, 1983; Baker et al., 1984), may be critical for specific synapse formation.

To examine mechanisms mediating the formation of specific connections, we have grown identified central neurons of the marine mollusc Aplysia californica in dissociated cell culture. A major advantage to using invertebrates, such as the leech (Ready and Nicholls, 1979; Fuchs et al., 1981, 1982; Henderson, 1983; Henderson et al., 1983), Helisoma (Wong et al., 1981; Hadley et al., 1983), or Aplysia (Kaczmarek et al., 1979; Dagan and Levitan, 1981; Camardo et al., 1983; Schacher and Proshansky, 1983; Bodmer et al., 1984) for studies in vitro is the ability to examine individual neurons that are large (facilitating electrophysiological and biochemical studies) and have well defincd patterns of interconncetions. For example, the cholinergic Aplysia neuron L10 in the abdominal ganglion re-establishes specific chemical connections in vitro with its normal follower cells but not with non-follower neurons containing acetylcholine receptors (Camardo et al., 1983).

In the present study we examined synapse formation between identified cell R2 and other abdominal ganglion neurons. The giant cell R2 is cholinergic based on a variety of biochemical studies (McCaman and Dewhurst, 1970; Giller and Schwartz, 1971; Eisenstadt et al., 1973), and it synapses only on mucus glands in the body wall (Rayport et al., 1983). We report here that R2 forms chemical connections with three other abdominal ganglion cells that do not receive input from $\mathrm{R} 2$ in vivo. The chemical connections that $\mathrm{R} 2$ torms with these cells have cholinergic and noncholinergic properties.

\section{Materials and Methods}

Tissue culture procedures. The methods used for the isolation and maintenance of Aplysia neurons in culture have been described (Schacher and Proshansky, 1983). Abdominal ganglia from 1- to 4-gm animals raised from fertilization at the Marine Biological Laboratory (Woods Hole, MA) (Kriegstein et al., 1974; Kriegstein, 1977b) were bathed in proteolytic enzyme, pinned in a Sylgard (Dow Corning, Midland, MI)-coated dish, and desheathed. The giant neuron R2, the left upper quadrant (LUQ) cells (L2 to LO), and neurons L11 and R15 were identified on the basis of size, position, pigmentation, and axon distribution. They were removed from the ganglion with portions of their axon branches and placed in polylysine-coated culture dishes with medium composed of Aplysia hemolymph and L-15 medium (Flow Laboratories, McLean, VA). The culture contained either R2 with either one cell type ( $L \cup Q, L 11$, or $R 15)$ or in combination with two or three different cells (see Fig. 1). After $24 \mathrm{hr}$ at room temperature, the cultures were maintained at $18^{\circ} \mathrm{C}$. Medium from the original stock was added to the dishes every other day.

Electrophysiology. The presence of chemical connections between the cells was examined in 4- to 7-day-old cultures by standard intracellular recording methods (Camardo et al., 1983) using single-barrelled electrodes 
of 5 to 10 megohms filled with either $2.5 \mathrm{M} \mathrm{KCl}$ or $4 \mathrm{M}$ potassium acetate. During the recordings, the cultures were perfused with buffered sea water, $\mathrm{pH}$ 7.6. Atropine sulfate or hexamethonium chloride (Sigma Chemical Co., St. Louis, MO) was added to the bath to a final concentration of $10^{-4} \mathrm{M}$. At this concentration, atropine blocks the acetylcholine (ACh)-evoked fast chloride conductance, and hexamethonium blocks the ACh-evoked fast excitatory response (Gerschenfeld, 1973). ACh was applied by iontophoresis from a 40-megohm electrode filled with $1 \mathrm{M}$ ACh (Sigma).

\section{Results}

R2 forms chemical connections in vitro. After 24 to $48 \mathrm{hr}$, cultured Aplysia neurons form an overlapping network of neuritic processes (Fig. 1). In 26 of 26 cultures in which R2 was co-cultured with various
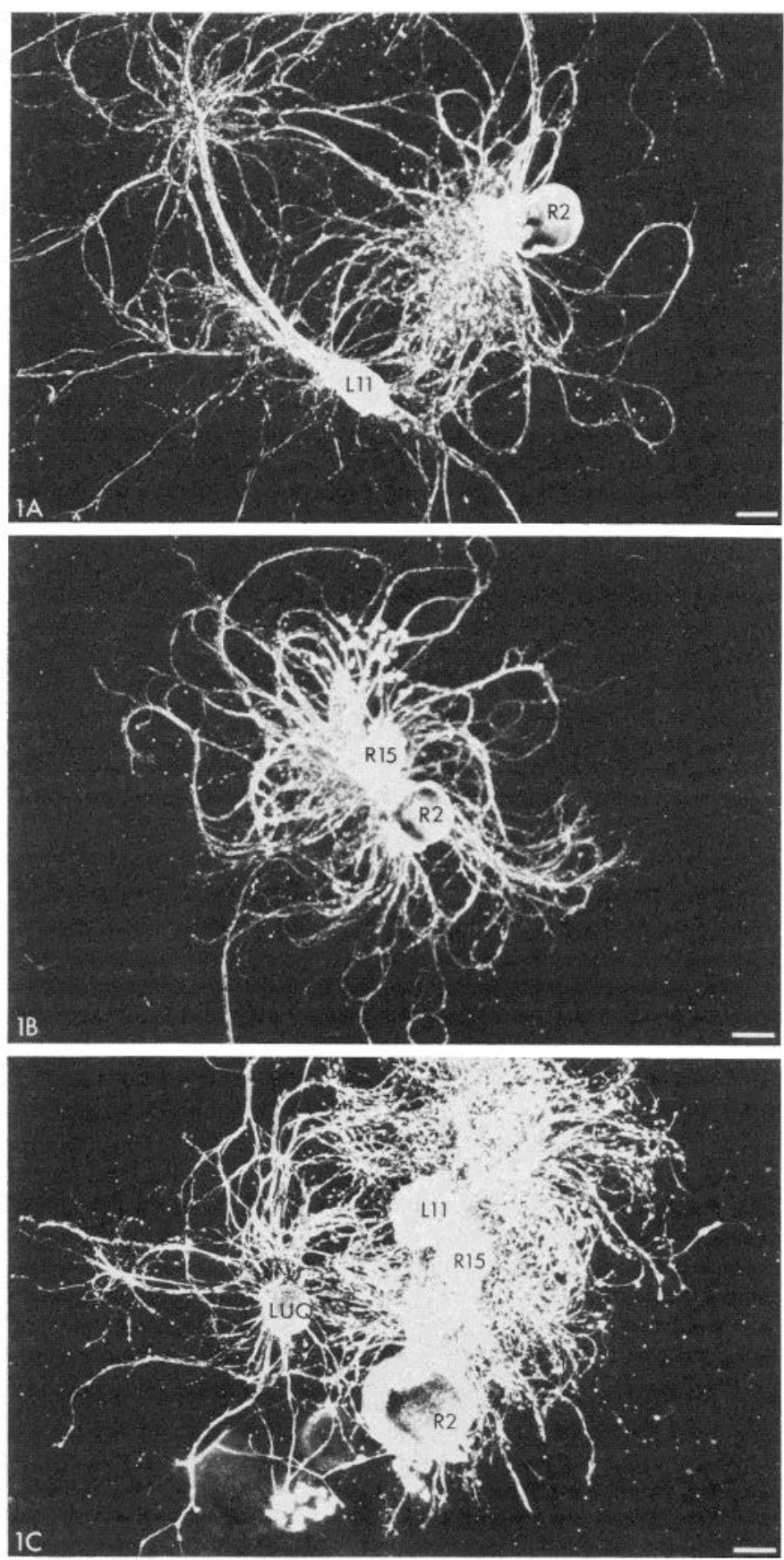

Figure 1. R2 cultured with LUQ cells, L11 and R15, after 4 days in culture. Note the extensive neuritic networks. A, R2 and L11 from a $1-\mathrm{gm}$ animal (stage 12). B, R2 and R15 from a 1-gm animal. C, R2 and three (LUQ, L11, and R15) target cells from a 3-gm animal (stage 12). The bars represent 100 $\mu \mathrm{m}$. combinations of LUQ cells ( $N=16$ cells), L11 ( $N=15$ cells), and $\mathrm{R} 15(N=10$ cells), chemical synaptic connections between R2 and the "target" cells were always detected. The connections were undirectional; action potentials in the target cells did not elicit a response in R2. Hyperpolarizing pulses in both R2 and target neurons showed no signs of electrotonic connections, indicating that the connections were chemical in nature. The electrophysiological properties of these connections also indicate that $\mathrm{R} 2$ may release more than one neurotransmitter.

R2 forms a dual-inhibitory connection with LUQ cells. R2 action potentials produce a dual-component IPSP on LUQ cells that has properties comparable to those evoked by other cholinergic neurons in vivo (Kandel, 1976) and in vitro (Camardo et al., 1983) (Fig. 2A). Action potentials in $\mathrm{R} 2$ always produce a hyperpolarization in the LUQ cells. The IPSP ranges in amplitude form 2 to $12 \mathrm{mV}$, has a latency of $20 \mathrm{msec}$, and has a duration of $800 \mathrm{msec}$. The fast and slow components of the PSP are best seen by eliciting a brief train of action potentials in R2 (Fig. 2, B and C). The fast component of the PSP can be reversed by hyperpolarizing the LUQ cells (Fig. $2 A_{2}$ ) beyond the reversal potential $(72 \pm 3 \mathrm{mV} ; N=10)$ and is sensitive to intracellular chloride concentration (Figs. 2, B and C).

The R2-LUQ connection in vitro shows pharmacological properties that are typical of inhibitory cholinergic synapses in Aplysia. The IPSP can be reversibly blocked by atropine (Fig. 2D) or with bath application of $1 \mu \mathrm{m} \mathrm{ACh}$. In addition, iontophoretic application of ACh produces responses in the LUQ cells that are similar to those seen for the R2 evoked responses (see Camardo et al., 1983) and are reversibly blocked by atropine (data not shown).

R2 forms a dual inhibitory-excitatory connection with L11. The connection formed between R2 and L11 has both a fast inhibitory and a slow excitatory component. Although both components are present in all R2-L11 connections $(N=15)$, the relative strength of each component can differ. In eight preparations, the excitatory component predominates (Fig. $3 A$ ). In these cases, a single action potential in R2 evokes action potentials in L11 (Fig. 3A) with a latency of about $40 \mathrm{msec}$. As L11 is hyperpolarized from the resting potential, the excitatory component first becomes smaller, the PSP is 1 to $2 \mathrm{sec}$ in duration (Fig. $3, A_{2}$ and $A_{3}$ ), and the latency remains at about $40 \mathrm{msec}$. With further hyperpolarization (Fig. $3 A_{4}$ ), the fast inhibitory component predominates; the PSP increases in amplitude (as the membrane potential is hyperpolarized further from the reversal potential), the PSP lasts only about $800 \mathrm{msec}$, and the latency shifts to $20 \mathrm{msec}$.

In other R2-L11 cultures $(N=7)$ both the fast inhibitory component and the slow excitatory component can be observed when L11 is maintained at its resting membrane potential ( 45 to $50 \mathrm{mV}$ ). The amplitude of the inhibitory component ranges from 0.5 to $4 \mathrm{mV}$ and the slow excitatory component ranges from 2 to $6 \mathrm{mV}$. As shown in Figure $3, B$ and $C$, action potentials in R2 evoke a dual inhibitoryexcitatory (I-E) response in L11. The fast inhibitory component in L11, like the fast component in LUQ cells (Fig. $2 C$ ), is most likely mediated by a change in chloride conductance since it can be abolished or reversed at resting membrane potentials after intracellular injection of chloride ions.

Pharmacological studies of the R2-L11 connection show that the fast inhibitory component can be blocked by atropine and is therefore likely to be cholinergic (Fig. 3C). As observed for the LUQ cells, the atropine block of the fast inhibitory component in L11 is reversible as well. lontophoresis of ACh onto the cell body or processes of L11 produces a hyperpolarization that is reversible by hyperpolarizing L11 and is blocked by atropine (Fig. 3D). In contrast, the slow excitatory response is not affected by cholinergic blocking agents such as atropine or hexamethonium, nor is it evoked by the iontophoresis of ACh.

$R 2-R 15$ connection is a noncholinergic slow IPSP. Action potentials in R2 produce a slow inhibitory response in R15 (1 to $8 \mathrm{mV}$ amplitude) with a latency of about $70 \mathrm{msec}$ and a duration of 3 to $10 \mathrm{sec}$ (Fig. 4, $A$ and $B$ ). In no R2-R15 culture $(N=10)$ did we see 

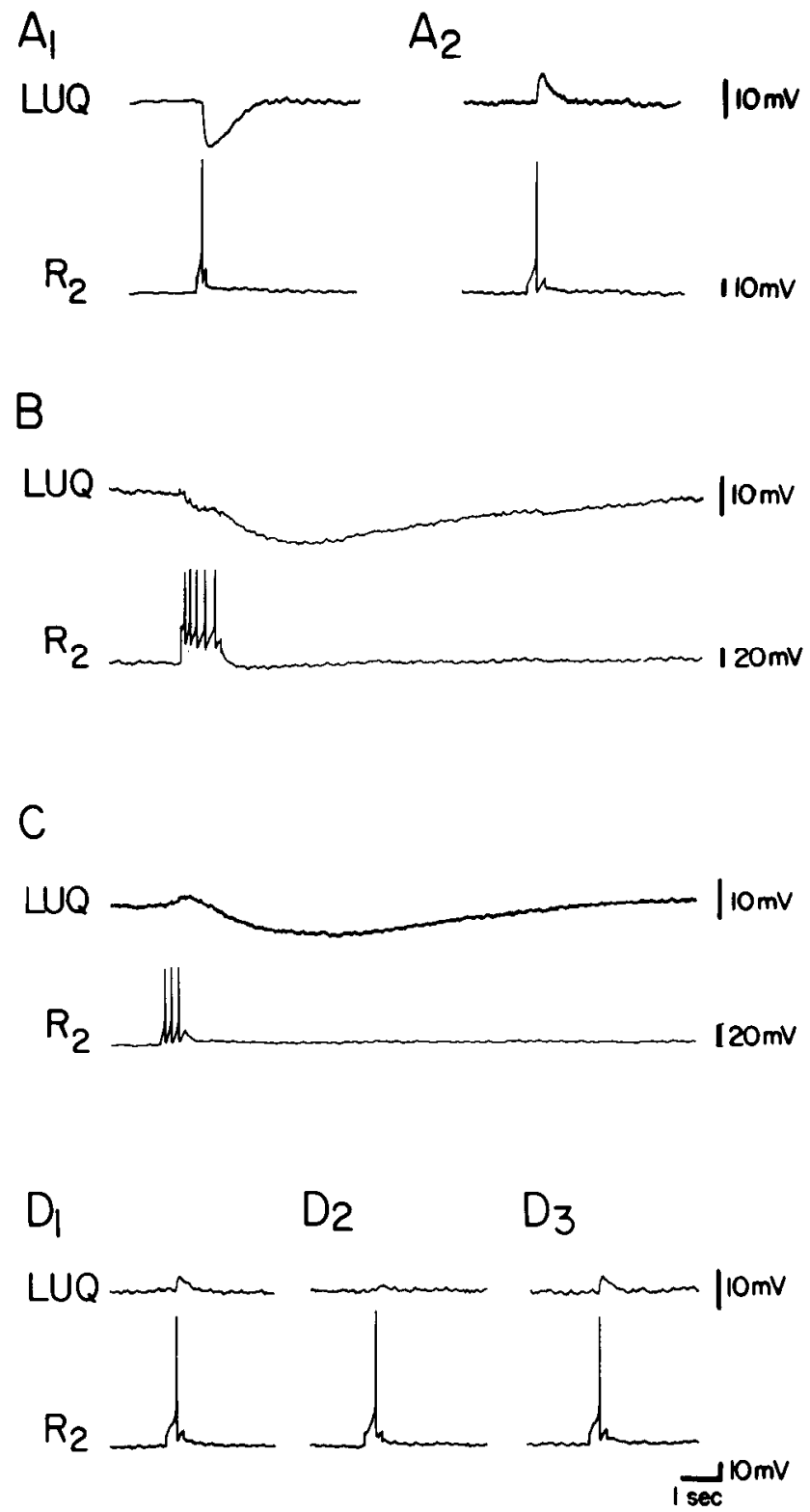

Figure 2. Properties of R2-LUQ connections. R2 evokes a dual fast inhibitory-slow inhibitory response in LUQ cells. A, A single action potential in $\mathrm{K} 2$ evokes a $12-\mathrm{mV}$ hyperpolarization in the $L U Q$ cell with a $20-\mathrm{msec}$ latency $\left(A_{1}\right)$. Hyperpolarizing the LUQ $40 \mathrm{mV}$ below its resting potential results in the reversal of the response evoked by $R 2\left(A_{2}\right)$. B, $A$ brief burst of action potentials in $\mathrm{R} 2$ evokes a dual-component hyperpolarization. The fast component is terminated with the offset of spikes in R2. The slow component, in contrast, long outlasts the stimulation. $C$. The fast component of the IPSP. but not the slow component, can be reversed at the resting potential by intracellular injection of chloride ions. After hyperpolarizing the LUQ cell shown in $B$ for $10 \mathrm{~min}$, a burst of action potentials now evokes a fast depolarization and slow hyperpolarization from the LUQ cell at the resting potential. $D$, The fast component of the R2-LUQ response is reversibly blocked by atropine (or bath application of $1 \mu \mathrm{M} \mathrm{ACh}$ ). Before application of $10^{-4} \mathrm{M}$ atropine, the LUQ cell was hyperpolarized $40 \mathrm{mV}$ below the resting potential to reverse the fast component. Action potentials in $\mathrm{R} 2$ gave a stable response in the LUQ cells $\left(D_{1}\right)$. After $2 \mathrm{~min}$ in atropine, the response in the LUQ cell was virtually abolished $\left(D_{2}\right)$. Five minutes after beginning the washout of the atropine, the LUQ response recovered to pre-atropine levels $\left(D_{3}\right)$. Atropine also produced the same effect on LUQ responses with ACh iontophoresis.

the fast excitatory response normally observed for cholinergic input onto R15 in the intact ganglion. The absence of a cholinergic response in $\mathrm{R} 15$ is observed in culture under conditions where R2 forms cholinergic connections with LUQ and L11 (for example, see
Fig. $1 C$ ). The IPSP in R15 can be nulled with hyperpolarization (null polential $=75 \mathrm{mV} \pm 3$ ) bul cannol be reversed (Fig. 4, $A$ and $\mathrm{B}$ ), and is not blocked with atropine or hexamethonium (data not shown). The inability to reverse the slow IPSP is typical for many slow synaptic potentials recorded in Aplysia central neurons in vivo. R15 does have cholinergic receptors, however, since iontophoresis of ACh on the cell body or processes of R15 evokes a depolarization which is the typical cholinergic response for this cell (Fig. 4C).

\section{Discussion}

$\mathrm{R} 2$ growing in vitro reliably forms strong chemical connections with identified abdominal ganglion neurons L11 and R15, and LUQ cells that do not receive input from $R 2$ in vivo (Table I). The synaptic connections form rapidiy, within 4 days, and are unidirectional; action potentials in the target neurons do not evoke responses in R2. The clectrophysiological and pharmacological properties of the R2-LUQ connection are typical of the normal cholinergic input to LUQ cells. The properties of the R2-L11 and R2-R15 connections, especially the slow excitatory component of the R2-L11 connection, and the slow hyperpolarization observed in R2-R15 connections, are not characteristic of their cholinergic input in vivo. This implies that R2 releases another neurotransmitter the actions of which evoke the noncholinergic responses. The results with R2 contrast with those found previously for L 10 , another cholinergic neuron in the abdominal ganglion (Table I). Under identical in vitro conditions, L10 forms specific connections with target cells, even in the presence of nontarget cells with ACh receptors (Camardo et al., 1983). In addition, the electrophysiological properties of the connections formed by L10 with several target cells replicate their normal cholinergic input (Schacher, 1982).

The developmental history of R2 may contribute to its permissive behavior regarding synapse formation. The abdominal ganglion of Aplysia develops gradually over a 1-month period (Kriegstein, 1977a). Neurons are added continuously to the ganglion as a result of the migration of postmitotic cells from nearby proliferative zones (Jacob, 1984). R2 is among the first neurons in the ganglion to differentiate (Kriegstein et al., 1974; Kandel et al., 1980; Rayport and Kandel, 1980). Since R2 innervates mucus gland cells over much of the animal's body surface (Rayport et al., 1983), and mucus secretion may be a critical factor during the metamorphic phase (Kriegstein, 1977b), it is likely that $\mathrm{R} 2$ has formed functional synaptic contacts with its peripheral targets when the ganglion contains only about 150 neurons, or $10 \%$ of the number of neurons (excluding bag cells) in the mature ganglion. Although we do not know when $L U Q$ cells, R15, and L11 first appear within the ganglion and begin to differentiate, it is possible that they never interact with R2's growth cones or neurites because of the temporal sequences of their respective development. The formation of specific electronic connections between regenerating Helisoma neurons, both in vivo and in vitro, occurs only when neurite outgrowth by both neurons is coincident in time and space (Hadley and Kater, 1983; Hadley et al., 1983). Thus, when R2 is placed in culture and isolated from its normal interactions, it may show limited selectivity in synapse formation when given a chance, perhaps for the first timc, to interact with other abdominal ganglion neurons. The isolation of $\mathrm{R} 2$ from its normal peripheral targets and/or its afferent synaptic input may remove some negative regulatory influences that normally make $\mathrm{R} 2$ refractory to additional synapse formation with other abdominal ganglion cells. For example, it has been suggested recently (Tal and Rotschenker, 1984) that the enhancement of sprouting by motor cells and synapse formation with peripheral muscle under certain conditions may involve the absence of a diffusible target-derived factor that would normally suppress sprouting and synapse formation. In addition, appropriate afferent input to some neurons may be critical for the formation of their specific patterns of connections or the stabilization of connections formed earlier in development (Hubel and Wiesel, 1970; LeVay et al., 1980). Since R2 can be co-cultured in a variety of sequences with its normal targets (Ambron et al., 

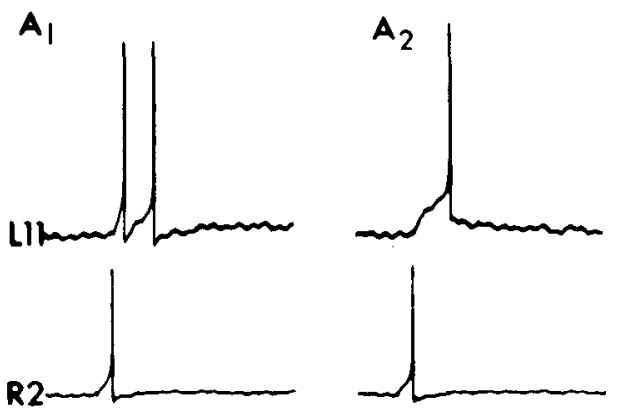

$\mathrm{A}_{3}$

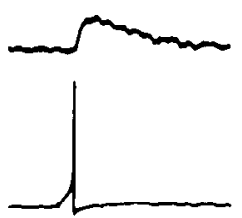

$A_{4}$

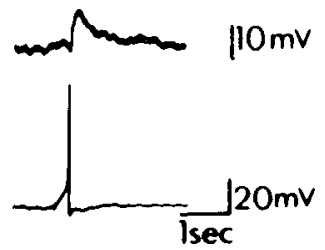

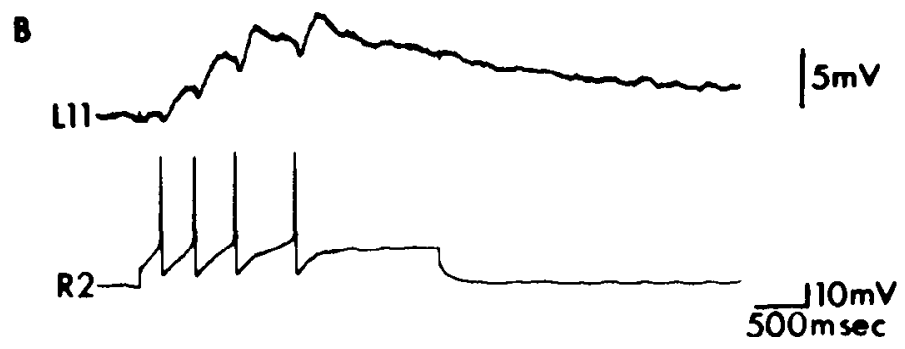
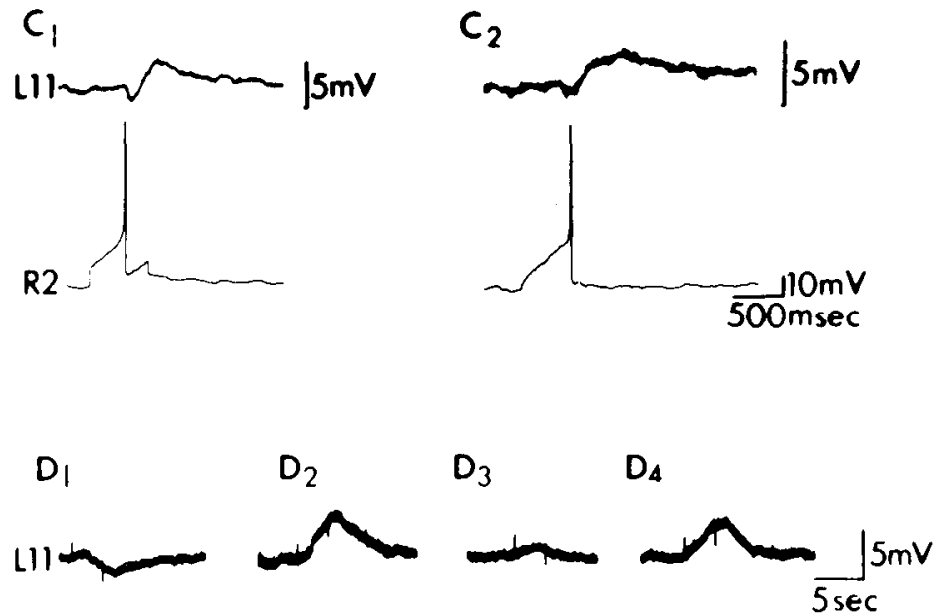

Figure 3. Properties of R2-L11 connections. R2 evokes a dual fast inhibitory-slow excitatory response in L11. A, R2-L11 connection with strong excitatory component and weak inhibitory component. At the resting potential, the R2 elicits a strong excitatory response in $\mathrm{L} 11$ resulting in two action potentials $\left(A_{1}\right)$. Hyperpolarization of $L 11$ by $10 \mathrm{mV}\left(A_{2}\right)$ results in a single action potential in $L 11$. Further hyperpolarization of $L 11$ to $30 \mathrm{mV}$ below resting levels results in a response that lasts about? $\sec \left(A_{3}\right)$. At $50 \mathrm{mV}$ below rest $\left(A_{4}\right)$, the latency of the $L 11$ response is reduced, the amplitude is now slightly greater than that seen at $30 \mathrm{mV}$, and the response lasts about $800 \mathrm{msec}$. $B, \mathrm{R} 2-\mathrm{L} 11$ connection with a dual-component fast inhibitory response and slow excitatory response. The first action potential of the burst in R2 produces a weak fast hyperpolarization and a 2-mV slow depolarization. Repetitive stimulation leads to frequency potentiation; with each action potential, the fast inhibitory component gets larger as L11's membrane potential becomes more depolarized. Note the long recovery of the response following the offset of the burst in $R 2$. $C$. The fast inhibitory component but not the excitatory component of the $L 11$ response is significantly reduced by atropine. A single action potential in $R 2$ evokes a dual response in $L 11\left(C_{1}\right)$. Three minutes after the application of atropine, the fast intibitory response is virtually absent, whereas the slow excitatory component is not affected $\left(C_{2}\right)$. D, ACh iontophoresis on L11 neurites evokes a hyperpolarizing response in L11, which reverses by hyperpolarizing $L 11$ from rest and is reversibly blocked with atropine. ACh application on L11 maintained at rest produces only a hyperpolarizing response $\left(D_{1}\right)$. After $L 11$ is hyperpolarized $50 \mathrm{mV}$ below resting levels, ACh now elicits a depolarizing response $\left(D_{2}\right)$. Three minutes atter application of atropine, the response to ACh is virtually abolished $\left(D_{3}\right)$ and is restored by 5 min after atropine washout $\left(D_{4}\right)$.

1985) or some of its presynaptic partners (Rayport and Kandel, 1980), it will be possible to examine whether these temporal and cell interactions can influence synapse formation by R2.

In contrast to the results described here for R2, previous studies showed that $\mathrm{L} 10$ forms connections with known target neurons but not with non-target cells that contain ACh receptors (Camardo et al., 1983). Thus, temporal factors and afferent input may not be critical for selective synapse formation by $L 10$ in vitro. Unlike $R 2$, $L 10$ is presynaptic to a specific subset of neurons in the abdominal ganglion. Additional factors may therefore be involved with L10's selection of appropriate target neurons.

The noncholinergic properties of the R2-L11 and R2-R15 connec- 


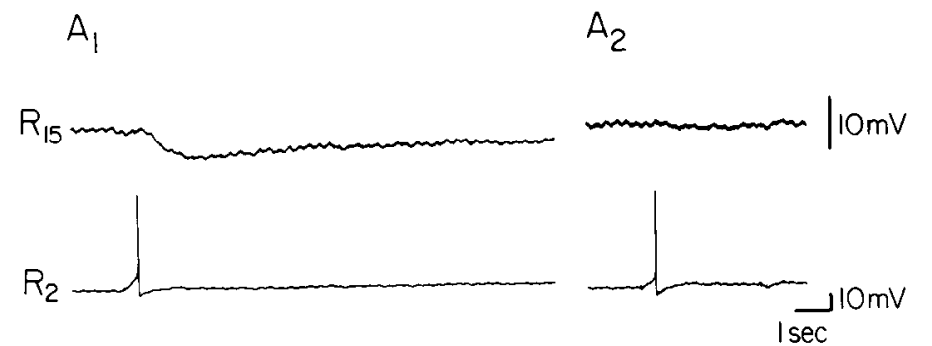

$B_{1} \quad B_{2}$

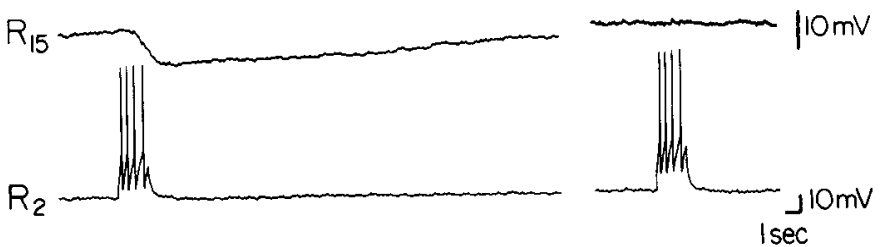

$\mathrm{C}_{1}$

$\mathrm{C}_{2}$
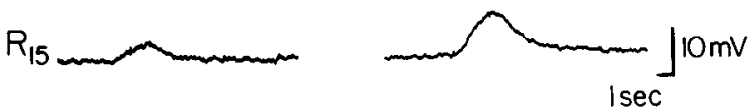

Figure 4. Properties of R2-R15 connection. This R2 evoked response in $\mathrm{R} 15$ is a slow hyperpolarization with a long latency. $A, A$ single spike in R2 evokes a long-lasting hyperpolarizing response in $\operatorname{R} 15\left(A_{1}\right)$. Hyperpolarizing R15 to $50 \mathrm{mV}$ below rest nulls the response but does not reverse it $\left(A_{2}\right)$. $B$, A burst of spikes in R2 elicits only the slow hyperpolarizing response in R15 with no fast excitatory component that is typical of R15's cholinergic input $\left(B_{1}\right)$. The long-lasting hyperpolarizing response in R15 is nulled but not reversed when $R 15$ is hyperpolarized $50 \mathrm{mV}$ below rest $\left(B_{2}\right)$. $C$, ACh iontophoresis onto the cell body $\left(C_{1}\right)$ and neurites $\left(C_{2}\right)$ of $R 15$ results in a depolarization.

TABLE I

Summary of $R 2$ and $L 10$ connections with $L U Q$ cells, $R 15$, and $L 11$

The properties for connections on LUQ cells, R15, and L11 by $R 2$ in vivo and in vitro, and the properties of connections onto these cells by a cholinergic cell $L 10$, both in vivo and in vitro, are summarized. See Segal and Koester (1980) for discussion of L10 connections in vivo and Camardo et al. (1983) and Schacher (1982) for $L 10$ connections in vitro.

\begin{tabular}{|c|c|c|c|c|c|}
\hline \multirow{3}{*}{$\begin{array}{l}\text { Postsynaptic } \\
\text { Ceell }\end{array}$} & \multicolumn{4}{|c|}{ Presynaptic Cell } & \multirow{3}{*}{$\begin{array}{c}\text { ACh } \\
\text { Response }\end{array}$} \\
\hline & \multicolumn{2}{|c|}{$\mathrm{R} 2$} & \multicolumn{2}{|c|}{ L10 } & \\
\hline & In vivo & In vitro & In vivo & In vitro & \\
\hline LUQ & $\mathrm{NC}^{a}$ & $l_{t} I_{S}$ & $t_{t} I_{s}$ & $I_{\mathbf{f}}-_{S}$ & $I_{f} I_{s}$ \\
\hline L11 & $\mathrm{NC}$ & $\mathrm{I}_{\mathrm{t}}-\mathrm{E}_{\mathrm{s}}$ & $I_{4}$ & ND & $\mathrm{l}_{f}$ \\
\hline R15 & NC & $I_{s}$ & $E_{f}$ & $E_{1}$ & $E_{f}$ \\
\hline
\end{tabular}

${ }^{a} N C$, no connection; $l_{f_{1}}$ fast inhibitory component; $l_{s_{1}}$ slow inhibitory component; $E_{s}$, slow excitatory component; $N D$, not determined; $E_{f}$, fast excitatory component.

tions suggest that, in vitro, $\mathrm{R} 2$ is releasing another neurotransmitter along with $\mathrm{ACh}$. This is best demonstrated when a single R2 is cocultured with two or three different target neurons (Fig. $1 \mathrm{C}$ and Fig. 2 in Ambron et al., 1985). In these cases, a single R2 forms an appropriate cholinergic connection with the LUQ cell, a dual-component (cholinergic and noncholinergic) connection with L11, and a noncholinergic connection with R15. It is not likely that the R2 evoked responses in $L 11$ and $R 15$ are caused by a novel $A C h$ receptorionophore since iontophoretic applications of ACh on the cell body and neurites of $\mathrm{L} 11$ and $\mathrm{R} 15$ result in the appropriate membrane polarizations with pharmacological properties identical to those observed in vivo. Recently, Brown et al. (1984) reported that R2 contains immunoreactivity for the neuropeptide Phe-Met-Arg-Pheamide (FMRF-amide). This peptide is also capable of producing both inhibitory and excitatory actions in abdominal ganglion neurons (Stone and Mayeri, 1981). Our preliminary data (Ambron et al., 1985a), indicating thal R2 in vivo and in vitro can synthesize FMRFamide and is likely to produce the noncholinergic components of the R2 evoked responses, support the presence of FMRF-amide in $\mathrm{R} 2$.

If $\mathrm{R} 2$ is releasing another transmitter in addition to $A C h$, why does the R2-R15 connection lack an appropriate cholinergic component? The cell is obviously competent to respond since iontophoresis of ACh on the R15 cell body or neurites evokes the characteristic depolarization indicating that the R15 surface has ACh receptors. It is possible that the $\mathrm{ACh}$ receptors on $\mathrm{R} 15$ are not clustered at the $R 2$ release site. A similar observation was observed in some $L 10-$ LUQ cultures, where under certain conditions the L10 evoked response in the LUQ cell lacked the fast inhibitory component although that receptor-ionophore was present on the LUQ cell body and neurites (Camardo et al., 1983). The absence of the normal cholinergic responsc in the R2 R15 connection may also result from the rapid degradation or diffusion of $\mathrm{ACh}$ following release from the presynaptic sites of $\mathrm{R} 2$ that are situated distant from the postsynaptic sites on R15. An examination of the morphological properties of R2R15 contacts would allow us to determine whether structural features of the R2-R15 interaction affect the functional properties of the connection.

Because R2 reliably forms strong chemical connections and is large enough for biochemical studies at the level of a single neuron, we have begun to examine some of the molecular changes associated with synapse formation in the following paper (Ambron et al., 1985b).

\section{References}

Ambron, R. T., P. Lloyd, M. S. Flaster, and S. Schacher (1985a) FMRF-amide. in neuron R2 of Aplysia: Evidence for its role as a second neurotransmitter. Soc. Neurosci. Abstr. 11: 483

Ambron, R. T., H. Den, and S. Schacher (1985b) Synaptogenesis by single identified neurons in vitro: Contributions of rapidly transported and newly synthesized proteins. J. Neurosci. 5: 2857-2865.

Anderson, A. (1978) Postembryonic development of the visual system of the locust. J. Embryol. Exp. Morphol. 46: 147-170

Archer, S. M., M. W. Dubin, and L. A. Stark (1982) Abnormal development of kitten retino geniculatc conncctivity in the absence of action potentials. Science 217: 743-745.

Baker, R. E., M. A. Corner, and A. M. Habels (1984) Effect of chronic suppression ol bioelectric aclivily on the development of sensory ganglion evoked responses in spinal cord explants. J. Neurosci. 4: 1187-1192.

Bodmer, R., D. Dagan, and I. B. Levitan (1984) Chemical and electrotonic connections between Aplysia neurons in primary culture. J. Neurosci. 4. 228-233.

Brown, R. V., A. I. Basbaum, and E. Mayeri (1984) Identification of FMRFamide immunoreactive neurons in the abdominal ganglion of Aplysia. Soc. Neurosci. Abstr. 10: 691

Camardo, J., E. Proshansky, and S. Schacher (1983) Identified Aplysia neurons form specific chemical synapses in culture. J. Neurosci. 3: 26142620.

Changeaux, J., and A. Danchin (1976) Selective stabilization of developing synapses, a mechanism for the specification of neuronal networks. Nature 264: 705-712.

Christian, C. N., M. P. Daniels, H. Sugiyama, Z. Vogel, L. Jacques, and P. $G$. Nelson (1978) A factor from neurons increases the number of acetylcholine receptor aggregates on cultured muscle cells. Proc. Natl. Acad. Sci. U. S. A. 75: 4011-4015.

Dagan, D., and I. B. Levitan (1981) Isolated identified Aplysia neurons in cell culture. J. Neurosci. 1: 736-740.

Edelman, G. M. (1983) Cell adhesion molecules. Science 219: 450-457

Eisenstadt, M., J. E. Goldman, E. R. Kandel, H. Koike, J. Koester, and J. H. Schwartz (1973) Intrasomatic injection of radioactive precursors for study- 
ing transmitter synthesis in identified neurons in Aplysia californica. Proc Natl. Acad. Sci. U. S. A. 70: 3371-3375.

Flaster, M. S., and E. R. Macagno (1984) Cellular interactions and pattern formation in the visual system of the branchiopod crustacean, Daphnia magna. III. The relationship between cell birthdates and cell fates in the optic lamina. J. Neurosci. 4: 1486-1498.

Fuchs, P. A., J. G. Nicholls, and D. F. Ready (1981) Membrane properties and selective connections of identified leech neurons in culture. J. Physiol. (Lond.) 316: 203-224.

Fuchs, P. A., L. P. Henderson, and J. G. Nicholls (1982) Chemical transmis sion between individual Retzius and sensory neurons of the leech in culture. J. Physiol. (Lond.) 323: 195-210.

Gerschenfeld, H. M. (1973) Chemical transmission in invertebrate central nervous systems and neuromuscular junctions. Physiol. Rev. 53: 1-119.

Giller, E., and J. H. Schwartz (1971) Choline acetyltransferase in identified neurons of abdominal ganglion of Aplysia californica. J. Neurophysiol. 34: 93-107.

Gottlieb, D. I., and L. Glaser (1980) Cellular recognition during neuronal development. Annu. Rev. Neurosci. 3: 303-318.

Hadley, R. D., and S. B. Kater (1983) Competence to form electrical connections is restricted to growing neurites in the snail, Helisoma. J. Neurosci. 3: 924-932.

Hadley, R. D., S. B. Kater, and C. S. Cohan (1983) Electrical synapse formation doponds on interaction of mutually growing neurites. Science 221: 466-468.

Harris, W. A. (1981) Neural activity and development. Annu. Rev. Physiol. 43: $689-710$.

Henderson, L. P. (1983) The role of 5-hydroxtryptamine as a transmitter between identified leech neurones in culture. J. Physiol. (Lond.) 339: 309324.

Henderson, L. P., D. P. Kuffler, J. Nicholls, and R. -J. Zhang (1983) Structural and functional analysis of synaptic transmission between identified leech neurones in culture. J. Physiol. (Lond.) 340: 347-358.

Hubel, D. H., and T. N. Weisel (1970) The period of susceptibility to the physiological effects of unilateral eye closure in kittens. J. Physiol. (Lond.) 206: 419-436.

Jacob, M. H. (1984) Neurogenesis in Aplysia californica resembles nervous system formation in vertebrates. J. Neurosci. 4: 1225-1239.

Jessell, T. M., R. E. Siegel, and G. V. Fischbach (1979) Induction of acetylcholine receptors on cultured skeletal muscle by a factor extracted from brain and spinal cord. Proc. Natl. Acad. Sci. U. S. A. 76: 5397-5401.

Kaczmarek, L., M. Finbow, J. P. Revel, and F. Strumwasser (1979) The morphology and coupling of Aplysia bag cells within the abdominal ganglion and in cell culture. J. Neurobiol. 10: 535-550.

Kandel, E. R. (1976) Cellular Basis of Behavior, W. H. Freeman, San Francisco.

Kandel, E. R., A. Kriegstein, and S. Schacher (1980) Development of the central nervous system of Aplysia in terms of the differentiation of its specific identifiable cells. Neuroscience 5: 2033-2063.

Kriegstein, A. R. (1977a) Development of the nervous system of Aplysia californica. Proc. Natl. Acad. Sci. U. S. A. 74: 375-378.
Kriegstein, A. R. (1977b) Stages in the post-hatching development of Aplysia californica. J. Exp. Zool. 999: 275-288.

Kriegstein, A. R., V. Castellucci, and E. R. Kandel (1974) Metamorphosis of Aplysia californica in laboratory culture. Proc. Natl. Acad. Sci. U. S. A. 71 3654-3658.

LeVay, S., T. N. Wiesel, and D. H. Hubel (1980) The development of ocular dominance columns in normal and visually deprived monkeys. J. Comp Neurol. 191: 1-51.

LoPresti V., E. R. Macagno, and C. Levinthal (1973) Structure and development of ncuronal connections in isogenic organisms: Ccllular interactions in the development of the optic lamina of Daphnia. Proc. Natl. Acad. Sci. U. S. A. 71: 1098-1102.

McCarnan, R. E., and S. A. Dewhurst (1970) Choline acetyltransferase in individual neurons of Aplysia californica. J. Neurochem. 17: 1421-1426.

Purves, R. R., and J. W. Lichtman (1980) Elimination of synapses in the developing nervous system. Science 210: 153-157.

Rakic, P. (1973) Kinetics of proliferation and latency between final cell division and onset of differentiation of cerebellar stellate and basket neurons. $J$. Comp. Neurol. 147: 523-546.

Rayport, S. G., and E. R. Kandel (1980) Developmental modulation of an identified electrical synapse: Functional uncoupling. J. Nes urophysiol. 44 555-567.

Rayport, S. G., R. T. Ambron, and J. Babiarz (1983) Identified cholinergic neurons R2 and LP1 control mucus release in 1 plysia J. Neurophysiol. 49: 864-876.

Ready, D. F., and J. G. Nicholls (1979) Identified neurones isolated from leech CNS make selective connexions in culture. Nature 281: 67-69.

Salpeter, M. M., S. Spanton, K. Holly, and T. R. Poeliski (1982) Brain extract causes acetylcholine receptor redistribution which mimics some early events at developing neuromuscular junctions. J. Cell Biol. 93: 417-425.

Sanes, J. R., D. H. Feldman, J. M. Cheney, and J. C. Lawrence, Jr. (1984) Brain extract induces synaptic characteristics in the basal lamina of cultured myotubes. J. Neurosci. 4: 464-473.

Schacher, S. (1982) Cellular interactions in the development of neurons in Aplysia. Neurosci. Res. Program Bull. 20: 870-877.

Schacher, S., and E. Proshansky (1983) Neurite regeneration by Aplysia neurons in dissociated cell culture. J. Neurosci. 3: 2403-2413.

Segal, M., and J. Koester (1980) Different cholinergic synapses converging onto neurons in Aplysia produce the same synaptic action. Brain Res. 199: $459-465$

Stone, L. S., and E. Mayeri (1981) Multiple actions of FMRF-amide on identified neurons in the abdominal ganglion of Aplysia. Soc. Neurosci. Abstr. 7: 636.

Tal, M., and S. Rotshenker (1984) Sprouting and synapse formation produced by carbocaine. J. Neurosci. 4: 458-463.

Thompson, W. (1983) Synapse elimination in neonatal rat muscle is sensitive to patterns of muscle use. Nature 302: 614-616.

Wong, R. G., R. D. Hadley, S. B. Kater, and G. C. Hauser (1981) Neurite outgrowth in molluscan organ and cell cultures: The role of conditioning factor(s). J. Neurosci. 1: 1008-1021. 